\title{
Enhanced Performance of Natural Polymer Coagulants For Dye Removal From Wastewater: Coagulation Kinetics, And Mathematical Modelling Approach
}

Ifeoma Amaoge Obiora-Okafo

Nnamdi Azikiwe University https://orcid.org/0000-0003-0768-7397

Okechukwu Dominic Onukwuli

Nnamdi Azikiwe University

Chinenye Adaobi Igwegbe ( $\nabla$ ca.igwegbe@unizik.edu.ng )

Nnamdi Azikiwe University https://orcid.org/0000-0002-5766-7047

Chijioke Elijah Onu

Nnamdi Azikiwe University

Monday Omotioma

Enugu State University of Science and Technology

\section{Research Article}

Keywords: Coagulation, Crystal Ponceau 6R, Natural organic polymers, Flocculation kinetics, Adsorption kinetics, Mass transfer.

Posted Date: September 20th, 2021

DOl: https://doi.org/10.21203/rs.3.rs-835800/v1

License: (c) (i) This work is licensed under a Creative Commons Attribution 4.0 International License.

Read Full License

Version of Record: A version of this preprint was published at Environmental Processes on March 24th, 2022. See the published version at https://doi.org/10.1007/s40710-022-00561-3. 


\section{Abstract}

This study explores the potentials of Brachystegia eurycoma coagulant (BEC) and Vigna subterranean coagulant (VSC) as natural organic polymers (NOPs) for the decolourisation of Crystal Ponceau 6R (AR $44)$ in wastewater. Materials characterisation studies were done on the precursors. Detailed kinetics study was employed. The decolourisation procedures were evaluated through time-dependent reduction in the concentration of particles, with the variation of the independent parameters. The proximate analysis showed protein contents of $19.77 \%$ and $18.15 \%$ for BEC and VSC, respectively. The functional test shows the presence of $-\mathrm{OH}, \mathrm{N}-\mathrm{H}$, and $\mathrm{C}=\mathrm{H}$. Surface morphological study reveals that some rough surfaces, different pores sizes, and compact-net structures were evidenced. The order of removal efficiency was VSC > BEC with an optimum of $88.8 \%$ and $73.3 \%$, respectively. The values of $K$ and $a$ obtained for BEC and VSC were $6.38 \times 10^{-4} \mathrm{Lmg}^{-1} \mathrm{~min}^{-1}, 1.8$ and $4.03 \times 10^{-3} \mathrm{~L} / \mathrm{mg}^{-1} \mathrm{~min}^{-1}, 1.9$, respectively. The coagulation time, $T_{a g}$ of 31.35 and 26.96 min for BEC and VSC respectively disclosed a quick coagulation. The coagulation-flocculation kinetics demonstrated that the process conforms to the pseudo-second-order model with $R^{2}>0.997$, suggesting that the rate-controlling mechanism is governed by chemisorption. The experimental data were well predicted by the cross-validation test, with percentage mean relative deviation modulus (M\%) of 3.26 and 2.54 for BEC and VSC, respectively. These coagulants have added meaningful progress in wastewater treatment by coagulation-flocculation while displaying significant adsorption features. Likewise, the usage of kinetics studies and particle behaviour modelling should be a prerequisite in water treatment processes.

\section{Article Highlights}

- The performances of plant seeds coagulants were investigated for colour removal.

- Vigna subterranean coagulant resulted in optimum colour removal of $88.8 \%$.

- Optimum colour removal of $73.3 \%$ was obtained via Brachystegia eurycoma coagulant.

- The coagulation-flocculation process conforms to the pseudo-second-order model with $\mathrm{R}^{2}>0.997$.

- The rate-controlling mechanism was governed by chemisorption.

\section{Introduction}

Due to the high contaminant contents of dye-containing wastewater, the news of its threat to human health and aquatic body is already established (Ishak et al. 2020; Obiora-Okafo et al. 2019; Sonal and Mishra 2021). Several works have been carried out on the removal of these pollutants from dyecontaining wastewater using NOPs employing the coagulation-flocculation process (Beltrán-Heredia et al. 2011a; Igwegbe and Onukwuli 2019; Onukwuli and Obiora-Okafo 2019; Zhao et al. 2020). Due to the mission of the world on sustainable development, research interests have shifted to using NOPs (comprising plant-based or animal-based) for wastewater treatment. These coagulants possess come significant advantages over chemical coagulants due to their low toxicity, low sludge production, cost- 
effectiveness, and biodegradability (Igwegbe and Onukwuli 2019; Obiora-Okafo et al. 2014; Obiora-Okafo and Onukwuli 2018).

A good selection of natural coagulant promotes large flocs formation bringing about rapid settling through adsorption of particles, charge neutralisation, sweep flocculation, and inter-particle bridging mechanisms (Igwegbe et al. 2021d; Onukwuli et al. 2019). The adsorption mechanism is common when NOPs are used as a coagulant due to their polymeric features (Beltrán-Heredia et al. 2011b). Hence, NOPs encourage floc sizes due to their ability to attract smaller particles, thereby generating larger flocs. These interactions are also enhanced when there is some affinity between polymer segments and particle surfaces. Therefore, particle-particle interaction by adsorption usually occurs through electrostatic forces, hydrogen bonding, as well as ionic bonding. Most NOPs are charge sensitive; naturally, they are anionic, cationic, or non-ionic (Cainglet et al. 2020).

Coagulation-flocculation kinetics study is very important in the realm of colloidal science. It is necessary because it finds application in the analysis of colloidal and hydrodynamic contacts involving particleparticle interactions (Gregory 2009). Coagulation-flocculation kinetics have been investigated using some methods; direct counting of the flocculating colloids employing an ultramicroscope, or a particle counter, which yields the most clear-cut results. However, because this method is time-consuming, it is not ideal for routine coagulation kinetics analysis. The bulk technique approach is a regularly employed procedure for coagulation-flocculation kinetics study because it monitors changes in the particle suspension with time (Obiora-Okafo et al. 2020; Trefalt et al. 2020). This time-dependent approach is rapid, easy to use, cost-effective, and suitable for multi-particle determination.

The dynamic nature of the coagulation rate addresses how rapidly or slowly a suspension of particles will flocculate. Coagulation-flocculation processes have been studied by some authors thereby showing how the rate of spherical particles are agglomerated due to Brownian motion, taking diffusion coefficient of particles as constant (Ani et al. 2012; Menkiti et al. 2009; Schick and Hubbard 2005). As a result of that, the coagulation-flocculation process is always assumed to be a second-order process, therefore, the kinetics data are fitted into a second-order kinetics equation. Brownian mode of collisions of spherical particles would be studied in detail since it captures the crucial kinetics of various mass transfer processes such as coagulation-flocculation, adsorption methods, and advanced oxidation practices.

The possibility of employing active protein components isolated from Brachystegia eurycoma (BE) and Vigna subterranean (VS) to remove Crystal Ponceau 6R (AR 44) in an aqueous solution is investigated in this study. Coagulation-flocculation functional parameters such as coagulation rate constant and order of reaction were uniquely deduced using Polymath v5.1 software. A mathematical model describing the transient behaviour of the process was adopted to predict the rate of charged spherical particle transmission towards the adsorbing particles during the process.

\section{Materials And Methods}




\subsection{Preparation and extraction of active coagulant}

Brachystegia eurycoma and Vigna subterranean seeds as shown in Fig. 1 were purchased from Enugu, Nigeria and milled to sizes of $63-600 \mu \mathrm{m}$ to accomplish the solubilisation of active constituents. Samples $(2 \mathrm{~g})$ were dispersed in distilled water of $0.5 \mathrm{M} \mathrm{NaCl}$ solution, agitated for 20 min using Magnetic agitator (Model 78HW, England), and sieved through Whatman, No. 42 and $125 \mathrm{~mm}$ diameter. The filtrate is labelled the crude extract, used as the coagulants at the required dosages. As required, fresh solutions were prepared frequently and kept refrigerated (Onukwuli and Obiora-Okafo 2019; Sonal et al. 2021).

\subsection{Characterisation of the Coagulants}

Proximate parameters of the precursors' seed powders were analysed (AOAC 1990). The chemical structure and functional groups were investigated using an FTIR spectrophotometer (IR Affinity, Shimadzu Kyoto, Japan). The spectra range were between $4000-400 \mathrm{~cm}^{-1}$. Surface morphologies analysis were performed using a scanning electron microscope (Phenom Prox., Eindhoven, Netherlands) and the images were presented after 3D reconstruction via Image J v1.53 (Ighalo et al. 2021; Pérez and Pascau 2013) at $\times 600$ magnification.

\subsection{Preparation of Synthetic Wastewater}

Crystal Ponceau 6R (AR 44) dye, having a molecular structure as presented in Fig. 2a was manufactured by May and Baker, England. To obtain the absorption spectrum of the dye, $1000 \mathrm{mgL}^{-1}$ of AR 44 was dissolved in distilled water (APHA-AWWA-WEF 1999). The solution was scanned against distilled water which is the blank in the range of 200-850 nm using a UV-visible spectrophotometer (Shimadzu, UVvisible, 1800). In addition, a stock solution of $1000 \mathrm{mgL}^{-1}$ of AR 44 was prepared by dissolving a weighed amounts in separate doses. The required concentrations of $10-100 \mathrm{mgL}^{-1}$ were prepared from the stock solution using the dilution method (Onukwuli et al. 2019). The wavelength obtained at maximum absorbance $\left(\lambda_{\max }\right)$ is shown in Fig. $2 b$.

\subsection{Coagulation Assay}

The coagulation action of the seed extracts were experimentally determined by the Jar test (Shankar et al. 2019). The jar test evaluated the coagulation activities of the active protein extracts from the precursors based on the procedures of Obiora-Okafo and Onukwuli (Obiora-Okafo and Onukwuli 2018). The jar test procedure was carried out using Phipps and Bird, VA, USA apparatus, involving 4 min of quick mixing speed at $100 \mathrm{rpm}$ and slow mixing speed of $40 \mathrm{rpm}$ for $25 \mathrm{~min}$. The suspensions were allowed to settle down and after 480 min of sedimentation, clarified samples from the beakers were collected for absorbance examination using a UV-visible spectrophotometer, set at $\lambda_{\max }$ of $511 \mathrm{~nm}$. A preliminary test was conducted to establish the optimum factors including $\mathrm{pH}$, coagulant dosage $\left(\mathrm{mgL}^{-1}\right)$, dye concentration $\left(\mathrm{mgL}^{-1}\right)$, settling time $(\mathrm{min})$, and temperature $(\mathrm{K})$. Finally, colour concentrations $\left(\mathrm{mgL}^{-1}\right)$ were measured by comparing absorbance to concentration on a graduation curve. (Obiora-Okafo et al. 
2018), while the colour removal efficiencies were calculated according to Eq. (1) (Obiora-Okafo and Onukwuli 2018).

Colour removal $(\%)=\left(\frac{C_{0}-C}{C_{0}}\right) \times 100$

where, $\mathrm{C}_{\mathrm{O}}$ and $\mathrm{C}$ represent the initial and final colour concentrations $\left(\mathrm{mgL}^{-1}\right)$ before and after the process, respectively.

The coagulation kinetics of spherical charged-particle contact was studied in this section following the Brownian diffusion mechanism (Perikinetics) (see Supplementary file, section S1). Also, the model equation that can predict the amount of particles transferred in the coagulation system at any given time was derived (see Supplementary file, section S2). The model equation (Eq. S47 in the Supplementary file) was confirmed using MATLAB 9.3 software at different contaminant concentrations during the process occurring at different operating time (McMahon 2007). MATLAB 9.3, proved to be a great code-based mathematical and engineering package used for solving numerous mathematical problems (Carnell 2003; McMahon 2007). The exactness of the model was checked using the percentage mean relative deviation modulus ( $\% M)$, of Eq. (2). Thus, it gives details on the mean deviation of the predicted data from experimented data (Oke et al. 2014).

$$
\% M=\left[\sum_{n=1}^{n} \frac{\left|M_{\exp }-M_{\text {pre }}\right|}{M_{\exp }}\right] \times \frac{100}{N}
$$

2

where $\mathbf{M}_{\text {exp }}=$ experimental data and $\mathbf{M}_{\text {pre }}=$ predicted data

From the M\% analysis, values fewer than 5 confirmed an exceptionally good fit; then, values between 5 and 10 denote reasonably good fit; also, values above 10 showed poor fit (Yousefi et al. 2013).

Additionally, some numerical tools such as: coefficient of determination $\left(\mathrm{R}^{2}\right)$, Chi-square $\left(\chi^{2}\right)$, F-test, and T-test were further applied to the model testing using Microsoft Excel 2010.

\section{Results And Discussion}

\subsection{Characterisation results}

\subsubsection{Proximate study}

Proximate analysis of the precursors as presented in Table 1 shows high moisture values indicating the coagulants' ability to absorb water, as well as, dissolves colour particles suspended in water (Obiora-Okafo and Onukwuli 2018). The reasonable amount of crude 
protein contents as recorded indicates the presence of active coagulation components. The values obtained agree with the literature that the protein contents of $\mathrm{BE}$ and VS are cationic poly-peptides (Igwegbe et al. 2021c; Ikegwu et al. 2009) . Fibre contents present is believed that the precursors were biological polymers having some visible fibrous structures when dispersed in an aqueous medium (Bolto and Gregory 2007; Onukwuli et al. 2019; Yin 2010) . The proximate results validate the use of the seed extracts as potential coagulants.

Table 1 Proximate characteristics of the proposed coagulants

S/No. Parameters

Values

\begin{tabular}{llll}
\hline & & $\begin{array}{l}\text { Brachystegia eurycoma } \\
\text { (Black timber) }\end{array}$ & $\begin{array}{l}\text { Vigna subterranean } \\
\text { (Bambara nut) }\end{array}$ \\
\hline 1. & Yield & 28.31 & 14.6 \\
\hline 2 & $\begin{array}{l}\text { Bulk density } \\
\left(\mathrm{gm}^{-1} \mathrm{~L}^{-1}\right)\end{array}$ & 0.235 & 0.241 \\
\hline 3. & $\begin{array}{l}\text { Moisture content } \\
(\%)\end{array}$ & 7.25 & 10.0 \\
\hline 4. & Ash content (\%) & 3.48 & 2.97 \\
\hline 5. & $\begin{array}{l}\text { Protein content } \\
(\%)\end{array}$ & 19.77 & 18.15 \\
\hline 6. & $\begin{array}{l}\text { Fibre content } \\
\text { (\%) }\end{array}$ & 2.20 & 1.64 \\
\hline 7. & $\begin{array}{l}\text { Carbohydrate } \\
(\%)\end{array}$ & 56.76 & 60.94 \\
\hline 8. & Fat content $(\%)$ & 10.53 & 6.30 \\
\hline
\end{tabular}

\subsubsection{FTIR analysis of the coagulants}

The spectra representation of BEC and VSC are shown in Figs. 3a-b, respectively. In Figs. 3a there is a slight absorption peak of $3965.52-3780.36 \mathrm{~cm}^{-1}$ attributing to the stretching vibration of $-\mathrm{OH}$, together with vibration of water absorbed (Igwegbe et al. 2021c) . Also, the $-\mathrm{OH}$ groups with a peak at $3070.58 \mathrm{~cm}^{-1}$ were also evidenced in Fig. $\mathbf{3 b}$. The free hydroxyl groups, confirm the occurrence of carboxylic acids, phenols, and alcohols in the coagulants. This band also links to the $\mathrm{O}-\mathrm{H}$ vibrations of cellulose, pectin, and lignin. Consequently, there is an agreement between the results of Table 1 and the spectral results indicating the presence of moisture, oil, and carbohydrate. Furthermore, the analysis 
revealed that the absorption peak for the amines was evidenced in $3348.32 \mathrm{~cm}^{-1}$ for aliphatic primary amine $(\mathrm{N}-\mathrm{H})$ and secondary amine of $3070.58 \mathrm{~cm}^{-1}$ for BEC and VSC respectively. Also, the presence of stretching signals, $\mathrm{N}-\mathrm{H}$ detects the existence of amino compounds, confirming the presence of protein in the powders as demonstrated in Table 1. In addition, a major group in the wider region of $2021.34 \mathrm{~cm}^{-1}$ and $2052.20 \mathrm{~cm}^{-1}$ specifies the existence of a $\mathrm{C}=\mathrm{O}$ group (carbonyl compound). There was also a strong adsorption peak at $694.36 \mathrm{~cm}^{-1}$ and $632.64 \mathrm{~cm}^{-1}$ for BEC and VSC respectively, showing the distinguishing occurrence for $\mathrm{C}-\mathrm{H}$ out of plane deformation which is typically comparative to the position and spatial geometry of the double bond (Coates 2006). Finally, the occurrence of moistures, proteins, and esters is confirmed by the FTIR spectral of BEC and VSC, as well as the proximate analysis provided in Table 1, justifying their usage as good sources of coagulants in this research.

\subsubsection{Morphological analysis of the coagulant}

SEM technology was used to examine the external morphologies of the coagulants in this investigation, as shown in Fig. 4 at 600x magnifications. The 3D reconstructed SEM images revealed well-developed pores of various sizes and shapes. As a result, pore sizes made up of micro-pores, macro-pores, and mesopores, together with their distributions, are confirmed unique features of NOPs. Therefore, a major pore size of $0.41 \mu \mathrm{m}^{2}$ was revealed in the histograms, as well as fibre lengths between $1.66-21.45 \mu \mathrm{m}$ and $2.11-17.94 \mu \mathrm{m}$ for BEC and VSC respectively as shown in Fig. 5. Varying fibre lengths are unique features of NOPs that enhance their multifunctional utilisation as coagulants and adsorbents (ObioraOkafo et al. 2018). Rough surfaces disclose that the coagulants are rough fibrous solids primarily made of cellulose and lignin, indicating that they are polymeric. The binding of particles to polymer chains via inter-particle bridging or electrostatic interactions improves sweep flocculation. Adsorption as a crucial mechanism in the procedure is also confirmed by small holes and rough surfaces seen on the coagulant morphologies (Igwegbe et al. 2021c; Obiora-Okafo et al. 2018). Furthermore, the structures also retain compact-net arrangements which are more conducive to particle flocculation owing to bridge aggregation. Finally, when compared to the branching structure, the compact-net structure is better for flocculation and particle-bridge creation among flocs (Zhu et al. 2012).

\subsection{Colour concentration/removal efficiency dependent on settling time}

The flocculation process involves particle interactions and a time-dependent interface of coagulant hydroxide formation, following the hydrolysis reaction (Liang et al. 2016; Obiora-Okafo et al. 2018). The time-dependent influence of colour concentration and its reduction efficiency is presented in Fig. 6. The 
percentage reduction in concentration as observed in $1000 \mathrm{mgBEC} / \mathrm{L}$ and $800 \mathrm{mgVSC} / \mathrm{L}$ results to $73.3 \%$ and $88.8 \%$ respectively. In addition, the sharp time reduction of 30 min specifies a speedy coagulation process that discloses the probable coagulation time $\left(T_{a g}\right)$. Moreover, this rapid reduction in concentration may perhaps be attributed to either charge neutralisation or its combination with sweep flocculation mechanism (Beltrán-Heredia et al. 2011a). As a result, after 30 minutes, the amount of particles accessible for flocculation diminishes, showing a gradual drop in colour concentration as the process progresses. This is most likely due to an intricate coagulation-flocculation procedure that may include the development of a net-like structure that does not take a long period. Therefore, the greater flocculation period could be related to the presence of a sorption mechanism that necessitates a longer process time. After $300 \mathrm{~min}$, there was no noticeable change in concentration, indicating that equilibrium has been reached. Consequently, due to the saturation of the active adsorption sites, the aggregate becomes destabilized, preventing further adsorption and, as a result, the settling period is prolonged (Beltrán-Heredia et al. 2011a; Onukwuli and Obiora-Okafo 2019). For these reasons, coagulationflocculation using NOPs in wastewaters is more efficient at low pH conditions. Analogous to these results, related studies have also been reported by Zhu et al. (2011) and Trinh and Kang (2011).

\subsection{Coagulation-flocculation kinetics representing Brownian motion}

Analysis was performed on a $95 \%$ confidence level to determine the order of coagulation-flocculation response, and the parameters gotten from the data regression analysis for BEC and VSC are provided in Table 2. The intercept and slope of the equation defining the kinetics of agglomeration were used to calculate the coagulation rate constant, K, and the order of reaction (Eq. S3, see Supplementary file). The coagulation proportionality constant that connects the reaction rate to the concentration of the reacting species is called the coagulation rate constant (Schick and Hubbard 2005). This denotes that each minute, $0.000638 \mathrm{mg} \mathrm{L}^{-1}$ and $0.00403 \mathrm{mg} \mathrm{L}^{-1}$ of colour particles were consistently attached to the polymer surfaces creating larger aggregates for BEC and VSC, respectively. From the calculation, the reaction order obtain was in agreement with the conventional principle of coagulation-flocculation being a second-order process (Menkiti et al. 2011; Schick and Hubbard 2005). Hence, the reaction order gotten confirms the optimum order for the process, showing a second-order reaction. Also, the correlation coefficient $\left(R^{2}\right)$ demonstrates good agreement that implies that the studied kinetic data is significant. $\mathrm{T}_{\text {ag }}$ is inversely proportional to the starting concentration of colour particles, proposing that the higher the contaminant concentration, the shorter the coagulation time required for elimination (Obiora-Okafo et al. 2019). Furthermore, the collision efficiency $(E)$ values explain the attainability assumption that particle collision between contaminants and coagulants is $100 \%$ efficient throughout the dispersion, implying that particles will stick together after bimolecular collision and that particle distribution or complex formation distribution will occur during the process (Obiora-Okafo et al. 2019).

Table 2 Coagulation Kinetics Parameters from Brownian Theory 


\begin{tabular}{|lll|}
\hline Parameters & $1000 \mathrm{mg} \mathrm{BEC} / \mathrm{L}$ & $\mathbf{8 0 0} \mathbf{~ m g ~ V S C} / \mathrm{L}$ \\
\hline$K(\mathrm{~L} / \mathrm{mgmin})$ & $6.38 \mathrm{E}^{-04}$ & $4.03 \mathrm{E}^{-03}$ \\
\hline$a$ & 1.8 & 1.9 \\
\hline$R^{2}$ & 0.981 & 0.969 \\
\hline Rate Equation $(-r)$ & $6.38 \times 10^{-4} \mathrm{C}^{2}$ & $4.03 \times 10^{-3} \mathrm{C}^{2}$ \\
\hline$T_{a g}(\mathrm{~min})$ & 31.35 & 26.96 \\
\hline$K_{1}(\mathrm{~L} / \mathrm{min})$ & $3.19 \mathrm{E}^{-04}$ & $2.02 \mathrm{E}^{-03}$ \\
\hline$\beta(\mathrm{L} / \mathrm{mgmin})$ & 0.000638 & 0.00403 \\
\hline$E\left(\mathrm{mg}^{-1}\right)$ & 1.00 & 1.00 \\
\hline
\end{tabular}

\subsection{The influence of time on particle behaviour}

Particles reduction behaviour as a function of time depicts the pattern at which colour concentrations are reduced. Figure 7 depicts the fluctuations in $C_{T}, C_{1}, C_{2}, C_{3}$, and $C_{4}$ for initially monodispersed particles obtained using Eqs. S26 - S29 in the Supplementary file, section S1. With increasing time, both the total colour concentration, $C_{t}$ and the concentration of the singlet species, $C_{1}$, drop monotonically. The concentrations $C_{2(\mathrm{t})}, C_{3(\mathrm{t})}$, and $C_{4(\mathrm{t})}$ go through a maximum since they are not present at the initial time and concentration. Due to an increase in the number of particle concentrations to the aggregate formation over time, the number of singlets appears to be decreasing faster than the overall number of particles (Igwegbe et al. 2021a; Taitelbaum and Koza 2000). The resultant effect of the bimolecular reaction results in a drop in the total number of particles. Furthermore, we discovered that the lower the $K$ value, the longer the coagulation time, giving rise to a slow rate and longer coagulation-flocculation process (Menkiti et al. 2009).

\subsection{Adsorption models}

Some attractions exist between polymer segments and particle surfaces during the flocculation process, which leads to adsorption (Bolto and Gregory 2007) . Consequently, some kinetic models such as pseudo-first-order, pseudo-second-order, and Elovich kinetic models (see Supplementary file, section S3) were involved to examine the rate at which particles are adsorbed onto polymer surfaces, as presented in Fig. 8. Thus, the kinetic factors obtained were summarised in Table 3 . Consequently, the $\mathrm{R}^{2}$ for the models was quite low when compared to the pseudo-second-order model. Furthermore, the 
experimental data agree well with the pseudo-second-order kinetic model data, with BEC and VSC having the lowest normalised standard deviation, $\Delta q(\%)$ values of $2.1 \%$ and 1.07 $\%$, respectively evaluated using Eq. S54 (see Supplementary file). Additionally, the coagulation-adsorption process is confirmed as a second-order process owing to an excellent fit of the second-order kinetic with an $\mathrm{R}^{2}$ of 0.999. More importantly, the Elovich model's moderate agreement expanded our knowledge of the adsorption-chemisorption procedure, suggesting selective adsorption without site rivalry, as shown in organic polymers (Feng et al. 2021; Lanan et al. 2021) , leading to the position of the Langmuir model in the sorption process (Obiora-Okafo et al. 2018) . Thus, chemisorption, which involves valence forces through electron sharing between polymers and pollutants, was found to affect the general rate of the adsorption process (Ghernaout et al. 2015; Igwegbe et al. 2021b) .

Table 3 Adsorption factors for colour removal.

\begin{tabular}{|c|c|c|c|c|c|}
\hline \multicolumn{6}{|c|}{ Pseudo-first-order kinetics } \\
\hline & $q_{e}, \exp (m g / g)$ & $\mathrm{q}_{\mathrm{e}}, \mathrm{cal}(\mathrm{mg} / \mathrm{g})$ & $K_{\mathrm{F} 1}\left(\min ^{-1}\right)$ & $\mathrm{R}^{2}$ & $\Delta \mathrm{q}(\%)$ \\
\hline $1000 \mathrm{mgBEC} / \mathrm{L}$ & 7.3 & 1.95 & 0.01 & 0.911 & 25.911 \\
\hline $800 \mathrm{mgVSC} / \mathrm{L}$ & 11.1 & 4.899 & 0.009 & 0.851 & 19.75 \\
\hline \multicolumn{6}{|c|}{ Pseudo-second-order kinetics } \\
\hline & $\mathrm{q}_{\mathrm{e}}, \mathrm{cal}(\mathrm{mg} / \mathrm{g})$ & $\mathrm{K}_{2}(\mathrm{~g} / \mathrm{mg} \mathrm{min})$ & $\mathrm{R}^{2}$ & $\mathrm{~h}(\mathrm{mg} / \mathrm{g} \mathrm{min})$ & $\Delta q(\%)$ \\
\hline $1000 \mathrm{mgBEC} / \mathrm{L}$ & 7.52 & 0.0836 & 0.997 & 4.73 & 2.1 \\
\hline $800 \mathrm{mgVSC} / \mathrm{L}$ & 11.76 & 0.0395 & 0.999 & 5.46 & 1.07 \\
\hline \multicolumn{6}{|l|}{ Elovich kinetics } \\
\hline & a & b & $\mathrm{R}^{2}$ & & \\
\hline $1000 \mathrm{mgBEC} / \mathrm{L}$ & 3362.83 & 2.028 & 0.925 & & \\
\hline $800 \mathrm{mgVSC} / \mathrm{L}$ & 14.77 & 0.759 & 0.933 & & \\
\hline
\end{tabular}

\subsection{The expectation of particles transfer rate}

The mass transfer rate was verified using particle concentration measurements that showed the investigational and projected transfer rates all through the coagulation-flocculation process, as shown in Fig. 9. In consequence, the projected results demonstrate that the rate of concentration reduction, 
resulting in the rate of mass transfer being rapid at the start of the process, resulting in a tight agreement between the actual and expected results. Due to this, the anticipated equilibrium point is closer to the experimental equilibrium (Oke et al. 2021).

Table 4 displays the results of statistical data comparing the investigational and projected data. The results indicate that the lower the percentage, the better the prediction. The value of $M \%$ lesser than 10 specifies a good prediction of investigational data. Also, the correlation coefficient of the predicted results gave positive correlation values of 0.816 and 0.950 for BEC and VSC respectively. Furthermore, the $\chi^{2}$ values greater than 0.05 are more significant than those less than 0.05 . During the coagulationflocculation, the projected contaminant particle decline pattern is likewise similar to Oke et al. (2021)'s earlier study.

Table 4 Modelling verification result

\begin{tabular}{|llllll|}
\hline Coagulants & $\boldsymbol{M} \%$ & $\boldsymbol{R}^{2}$ & $\chi^{2}$ & F-test & T-test \\
\hline BEC & 3.263 & 0.816 & 30.30 & 0.711 & 0.0270 \\
\hline VSC & 2.536 & 0.950 & 23.98 & 0.0316 & 0.0316 \\
\hline
\end{tabular}

\section{Conclusion}

Natural organic polymers were found to be effective at removing colour from AR 44 dye effluent in this study. The proximate, FTIR, and SEM analysis done on the coagulants showed that BE and VS have the characteristics of possible coagulants. The characterisation results also revealed the coagulant's capability to disrupt contaminant particles due to their cationic nature, adsorb particles on its surfaces, improve floc formation due to their polymer features, and then enhance large settleable flocs due to particle linking and sweep flocculation mechanisms. The obtained values of $\mathrm{K}$ and $a$ agreed with the traditional assumption that rapid coagulation shows a second-order process. The adsorption procedure was more of a second-order process, demonstrating that the rate is proportional to the square of the particle concentration. These findings further suggested that in general, coagulation and adsorption processes were second-order processes governed by the chemisorption mechanism. The model investigated could be used to control colour particle transfer at any given condition and forecast the rate at which particles are transferred in a process without needing an experimental technique. It could also be utilized to extrapolate space and time that aren't stated by the experimental results. In this study, the coagulation-flocculation and adsorption capabilities of BEC and VSC were credited with their efficiency. Generally, this research has demonstrated the utilization of kinetics research in the large field of wastewater treatment and other mass-transfer processes.

\section{Declarations}

\section{Disclosure statements}


Funding: No external funding was received for the study.

Conflict of Interest: The authors proclaim no conflicts of interest.

Compliance with Ethical Standards: There is no research using human or animal subjects in this article.

Availability of data and materials (data transparency): All data and materials, as well as the software application, used to support their published claims and comply with field standards.

Code availability (software application or custom code): Not available

Authors' contributions: Conceptualisation: Ifeoma Amaoge Obiora-Okafo, Okechukwu Dominic Onukwuli; Methodology: Ifeoma Amaoge Obiora-Okafo, Okechukwu Dominic Onukwuli; Formal analysis and investigation: Ifeoma Amaoge Obiora-Okafo, Chinenye Adaobi Igwegbe; Writing - Ifeoma Amaoge ObioraOkafo, Chinenye Adaobi Igwegbe; Writing - review and editing: Ifeoma Amaoge Obiora-Okafo, Okechukwu Dominic Onukwuli, Chinenye Adaobi Igwegbe, Chijioke Elijah Onu, Monday Omotioma; Resources: Ifeoma Amaoge Obiora-Okafo; Supervision: Okechukwu Dominic Onukwuli

\section{Acknowledgement}

The authors would love to acknowledge the Department of Chemical Engineering, Nnamdi Azikiwe University, Awka, Nigeria, and Energy Research Centre, University of Nigeria, Nsukka, Nigeria for making available their facilities for this study. This study received no specific support from public, private, or nonprofit funding bodies.

\section{References}

1. Ani J, Nnaji N, Onukwuli O, Okoye C (2012) Nephelometric and functional parameters response of coagulation for the purification of industrial wastewater using Detarium microcarpum. J Hazard Mater 243:59-66. https://doi.org/10.1016/j.jhazmat.2012.09.069

2. AOAC (1990) Official Methods of Analysis, 15th edn. Association of Official Analytical Chemists, Washington D C

3. APHA-AWWA-WEF (1999) Standard Methods for the Examinations of Water and Wastewater, 21st edn. American Public Health Association, American Water Works Association, and Water Environment Federation, Washington, DC, pp 362-372

4. Beltrán-Heredia J, Sánchez-Martín J, Dávila-Acedo M (2011a) Optimization of the synthesis of a new coagulant from a tannin extract. J Hazard Mater 186:1704-1712. https://doi.org/10.1016/j.jhazmat.2010.12.075

5. Beltrán-Heredia J, Sánchez-Martín J, Rodríguez-Sánchez M (2011b) Textile wastewater purification through natural coagulants. Appl Water Sci 1:25-33. https://doi.org/10.1007/s13201-011-0005-2 
6. Bolto B, Gregory J (2007) Organic polyelectrolytes in water treatment. Water Res 41:2301-2324. https://doi.org/10.1016/j.watres.2007.03.012

7. Cainglet A, Tesfamariam A, Heiderscheidt E (2020) Organic polyelectrolytes as the sole precipitation agent in municipal wastewater treatment. J Environ Manage 271:111002. https://doi.org/10.1016/j.jenvman.2020.111002

8. Carnell AC (2003) MATLAB applications in chemical engineering. North Carolina State University 9. Coates J (2006) Interpretation of infrared spectra, a practical approach Encyclopedia of analytical chemistry: applications, theory and instrumentation

10. Feng Q, Gao B, Yue Q, Guo K (2021) Flocculation performance of papermaking sludge-based flocculants in different dye wastewater treatment: Comparison with commercial lignin and coagulants. Chemosphere 262:128416. https://doi.org/10.1016/j.chemosphere.2020.128416

11. Ghernaout D, Al-Ghonamy Al, Boucherit A, Ghernaout B, Naceur MW, Ait Messaoudene N, Aichouni M, Mahjoubi AA, Elboughdiri NA (2015) Brownian motion and coagulation process. American Journal of Environmental Protection 4:1-15. doi:10.11648/j.ajeps.s.2015040501.11

12. Gregory J (2009) Monitoring particle aggregation processes. Adv Colloid Interface Sci 147:109-123. https://doi.org/10.1016/j.cis.2008.09.003

13. Ighalo JO, Adeniyi AG, Igwegbe CA (2021) 3D Reconstruction and Morphological Analysis of Electrostimulated Hyperthermophile Biofilms of Thermotoga neapolitana. Biotech Lett 1-7. http://dx.doi.org/10.1007/s10529-021-03123-z

14. Igwegbe CA, Ighalo JO, Onukwuli OD, Obiora-Okafo IA, Anastopoulos I (2021a) Coagulationflocculation of aquaculture wastewater using green coagulant from Garcinia kola seeds: parametric studies, kinetic modelling and cost analysis. Sustainability 13:9177. https://doi.org/10.3390/su13169177

15. Igwegbe CA, Ighalo JO, Onyechi KK, Onukwuli OD (2021b) Adsorption of Congo red and malachite green using $\mathrm{H}_{3} \mathrm{PO}_{4}$ and $\mathrm{NaCl}$-modified activated carbon from rubber (Hevea brasiliensis) seed shells. Sustain Water Resour Manag 7:1-16. https://doi.org/10.1007/s40899-021-00544-6

16. Igwegbe CA, Onukwuli OD (2019) Removal of total dissolved solids (TDS) from aquaculture wastewater by coagulation-flocculation process using Sesamum indicum extract: effect of operating parameters and coagulation-flocculation kinetics. The Pharmaceutical Chemical Journal 6:32-45

17. Igwegbe CA, Onukwuli OD, Ighalo JO, Menkiti MC (2021c) Bio-coagulation-flocculation (BCF) of Municipal Solid Waste Leachate using Picralima Nitida Extract: RSM and ANN Modelling. Curr Opin Green Sustain Chem 4:100078. http://dx.doi.org/10.1016/j.crgsc.2021.100078

18. Igwegbe CA, Onukwuli OD, Ighalo JO, Umembamalu CJ (2021d) Electrocoagulation-flocculation of aquaculture effluent using hybrid iron and aluminium electrodes: A comparative study. Chem Eng J Adv 6:100107. http://dx.doi.org/10.1016/j.ceja.2021.100107

19. Ikegwu OJ, Oledinmma NU, Nwobasi VN, Alaka IC (2009) Effect of processing time and some additives on the apparent viscosity of 'achi' Brachystegia eurycoma flour. J Food Technol 7:34-37 
20. Ishak SA, Murshed MF, Md Akil H, Ismail N, Md Rasib SZ, Al-Gheethi AAS (2020) The application of modified natural polymers in toxicant dye compounds wastewater: a review. Water 12:2032

21. Lanan FABM, Selvarajoo A, Sethu V, Arumugasamy SK (2021) Utilisation of natural plant-based fenugreek (Trigonella foenum-graecum) coagulant and okra (Abelmoschus escluentus) flocculant for palm oil mill effluent (POME) treatment. J Environ Chem Eng 9:104667. https://doi.org/10.1016/j.jece.2020.104667

22. Liang L, Tan J, Peng Y, Xia W, Xie G (2016) The role of polyaluminum chloride in kaolinite aggregation in the sequent coagulation and flocculation process. J Colloid Interface Sci 468:57-61. https://doi.org/10.1016/j.jcis.2016.01.039

23. McMahon D (2007) MATLAB demystified. McGraw-Hill New York

24. Menkiti M, Nnaji P, Onukwuli O (2009) Coag-flocculation kinetics and functional parameters response of periwinkle shell coagulant (PSC) to $\mathrm{pH}$ variation in organic rich coal effluent medium. Nature Science 7:1-18

25. Menkiti M, Onyechi C, Onukwuli O (2011) Evaluation of perikinetics compliance for the coagflocculation of brewery effluent by Brachystegia eurycoma seed extract. Int J Multidiscip Sci Eng 2:77-83

26. Obiora-Okafo I, Menkiti M, Onukwuli O (2014) Utilization of response surface methodology and factor design in micro organic particles removal from brewery wastewater by coagulation/flocculation technique. Inter J of Appl Sci Maths 1:15-21

27. Obiora-Okafo I, Onukwuli O, Eli-Chukwu N (2020) Evaluation of bio-coagulants for colour removal from dye synthetic wastewater: characterization, adsorption kinetics, and modelling approach. Water SA 46:300-312. https://doi.org/10.17159/wsa.2020.v46i2.8246

28. Obiora-Okafo I, Onukwuli O, Ezugwu C (2019) Application of kinetics and mathematical modelling for the study of colour removal from aqueous solution using natural organic polymer. Desalin Water Treat 165:362-373. https://doi.org/doi:10.5004/dwt.2019.24507

29. Obiora-Okafo IA, Onukwuli OD (2018) Characterization and optimization of spectrophotometric colour removal from dye containing wastewater by coagulation-flocculation. Pol J Chem Tech 20:49-59. doi:http://dx.doi.org/10.2478/pjct-2018-0054

30. Obiora-Okafo IA, Onukwuli OD, Omotioma M (2018) The Relevance of Adsorption Mechanism on Spectrometric Colour Removal: Investigation of Optimum Operation Parameters. Der Pharma Chemica 10:139-151

31. Oke E, Arinkoola A, Salam K (2014) Mathematical modeling of mass transfer rate during injection of $\mathrm{CO}_{2}$ into water and surfactant solution. Pet Coal 56:54-61

32. Oke E, Okolo B, Adeyi O, Agbede O, Nnaji P, Adeyi J, Osoh K, Ude C (2021) Black-box modelling, biobjective optimization and ASPEN batch simulation of phenolic compound extraction from Nauclea latifolia root. Heliyon 7:e05856. https://doi.org/10.1016/j.heliyon.2020.e05856

33. Onukwuli O, Obiora-Okafo I (2019) Performance of polymer coagulants for colour removal from dye simulated medium: Polymer adsorption studies. Indian J Chem Technol 26:205-215 
34. Onukwuli OD, Obiora-Okafo IA, Omotioma M (2019) Characterization and colour removal from an aqueous solution using bio-coagulants: response surface methodological approach. Journal of Chemical Technology Metallurgy 54:77-89

35. Pérez JMM, Pascau J (2013) Image processing with ImageJ. Packt Publishing Ltd

36. Schick M, Hubbard A (2005) Coagulation and flocculation: Experimental and modelling studies, structure formation in dispersed systems, Taylor \& Francis Group, LLC, Surfactant Science Series 126:162-813

37. Shankar YS, Ankur K, Bhushan P, Mohan D (2019) Utilization of water treatment plant (WTP) sludge for pretreatment of dye wastewater using coagulation/flocculation. In: Advances in Waste Management. Springer, pp 107-121. https://doi.org/10.1007/978-981-13-0215-2_8

38. Sonal S, Mishra BK (2021) Role of coagulation/flocculation technology for the treatment of dye wastewater: trend and future aspects. In: Water pollution and management practices. Springer, pp 303-331. http://dx.doi.org/10.1007/978-981-15-8358-2_13

39. Sonal S, Ugale D, Mishra BK (2021) Combining surface water with mine water to improve the removal of natural organic matter by enhanced coagulation. Mine Water Environ (2021). https://doi.org/10.1007/s10230-020-00737-z

40. Taitelbaum H, Koza Z (2000) Kinetics and segregation at a single trap. J Mole Liq 86:305-312. https://doi.org/10.1016/S0167-7322(99)00153-1

41. Trefalt G, Cao T, Sugimoto T, Borkovec M (2020) Heteroaggregation between charged and neutral particles. Langmuir 36:5303-5311. https://doi.org/10.1021/acs.langmuir.0c00667

42. Trinh TK, Kang LS (2011) Response surface methodological approach to optimize the coagulationflocculation process in drinking water treatment. Chem Eng Res Des 89:1126-1135. https://doi.org/10.1016/j.cherd.2010.12.004

43. Yin C-Y (2010) Emerging usage of plant-based coagulants for water and wastewater treatment Process Biochem. 45:1437-1444. https://doi.org/10.1016/j.procbio.2010.05.030

44. Yousefi A, Niakousari M, Moradi M (2013) Microwave assisted hot air drying of papaya (Carica papaya L.) pretreated in osmotic solution. Afr J Agric Res 8:3229-3235. https://doi.org/10.5897/AJAR12.180

45. Zhao C, Zhou J, Yan Y, Yang L, Xing G, Li H, Wu P, Wang M, Zheng H (2020) Application of coagulation/flocculation in oily wastewater treatment: A review. Sci Total Environ:142795. https://doi.org/10.1016/j.scitotenv.2020.142795

46. Zhu G, Zheng H, Chen W, Fan W, Zhang P, Tshukudu T (2012) Preparation of a composite coagulant: Polymeric aluminum ferric sulfate (PAFS) for wastewater treatment. Desalination 285:315-323. https://doi.org/10.1016/j.desal.2011.10.019

47. Zhu G, Zheng H, Zhang Z, Tshukudu T, Zhang P, Xiang X (2011) Characterization and coagulationflocculation behavior of polymeric aluminum ferric sulfate (PAFS). Chem Eng J 178:50-59. https://doi.org/10.1016/j.cej.2011.10.008 
Figures
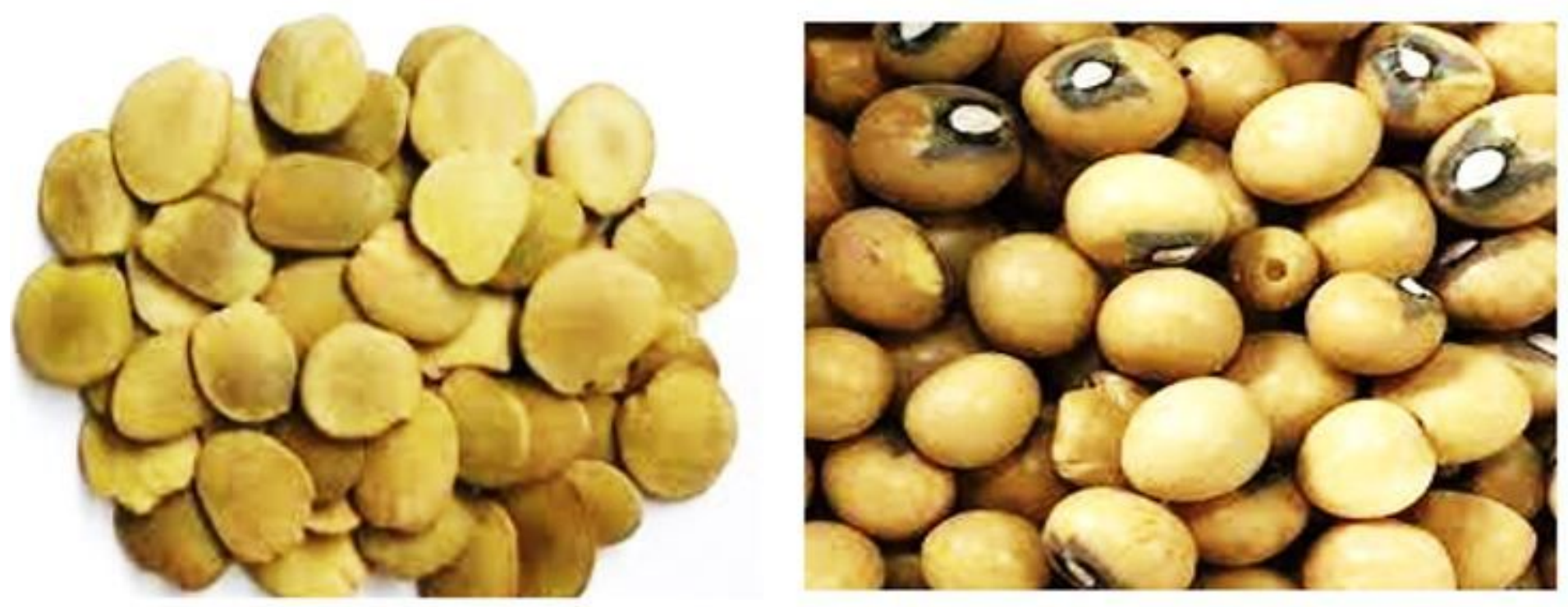

Figure 1

Dried seeds of a) Brachystegia eurycoma, and b) Vigna subterranean
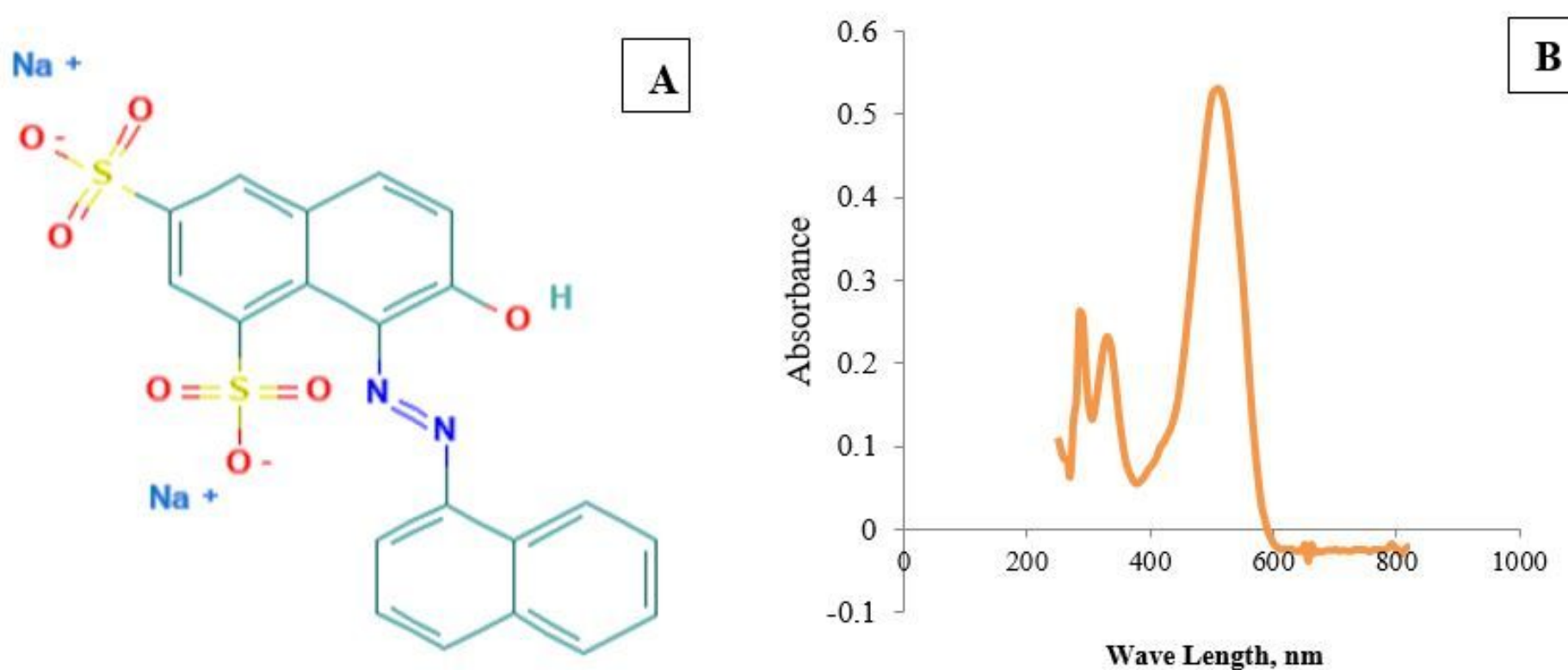

Wave Length, nm

Figure 2

(a) Structure of AR 44, (b) Spectrum analysis of AR 44 


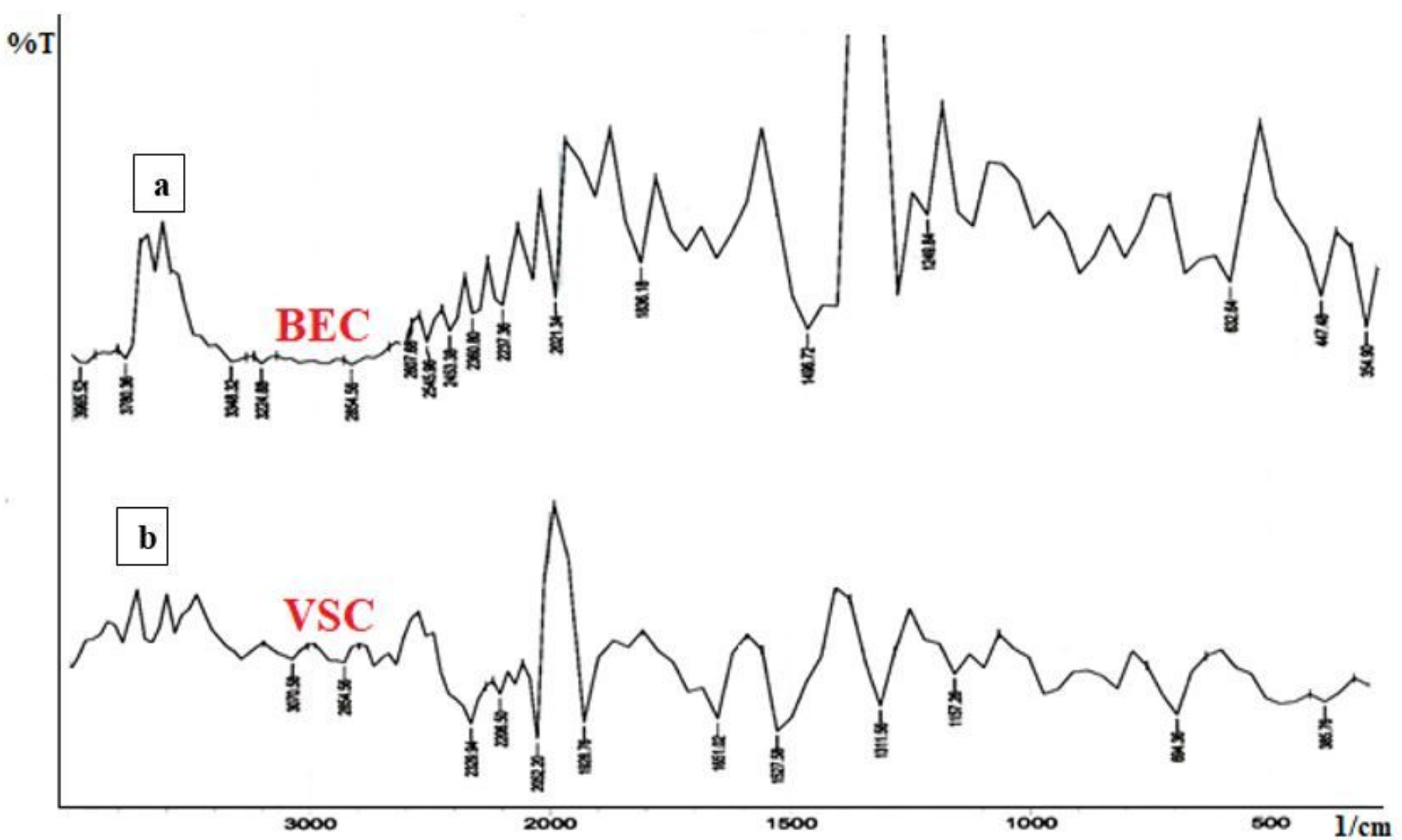

Figure 3

FTIR spectra of (a) BEC and (b) VSC 

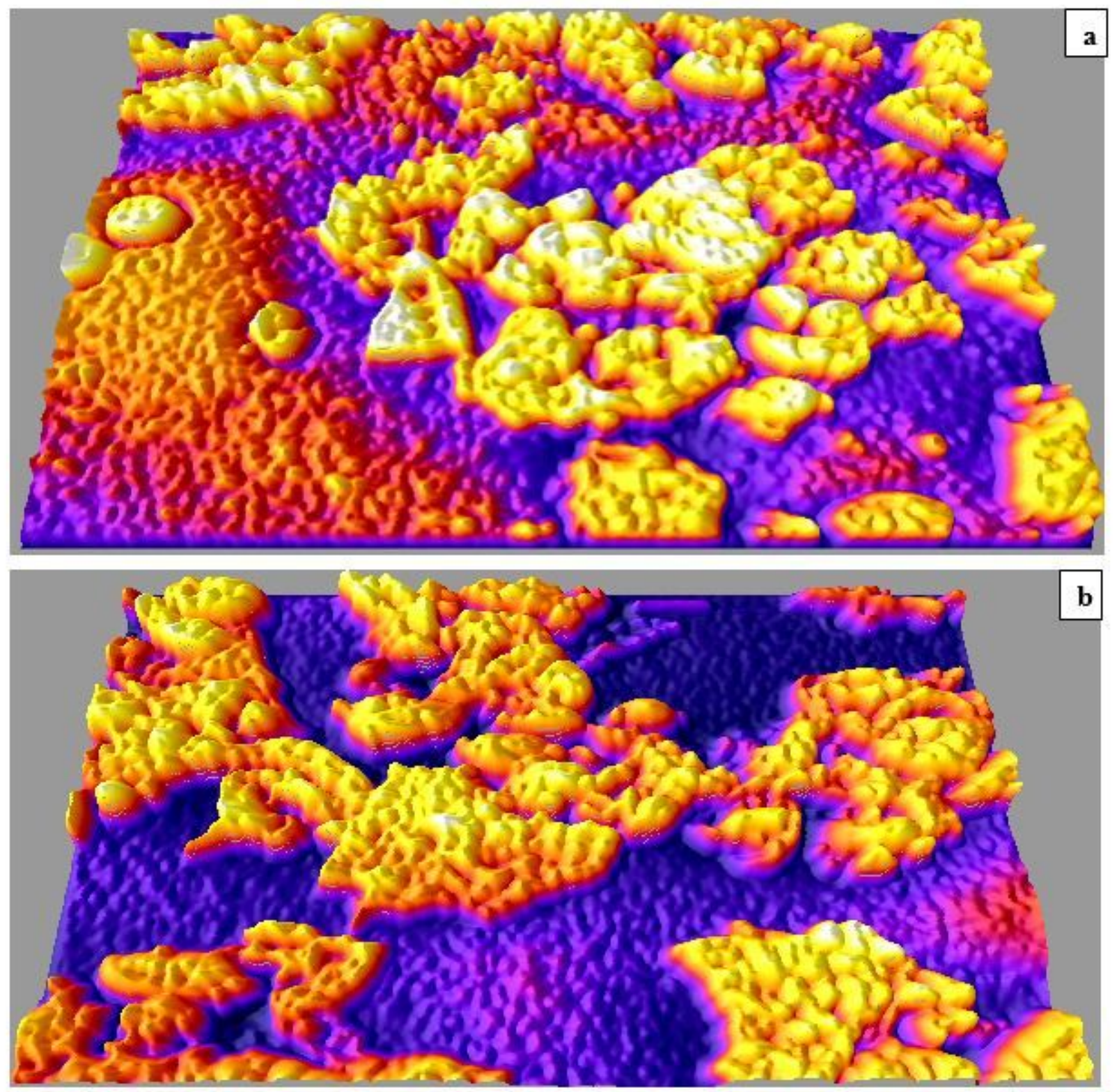

Figure 4

3D reconstructed SEM micrographs for (a) BEC and (b) VSC (600× magnifications) 

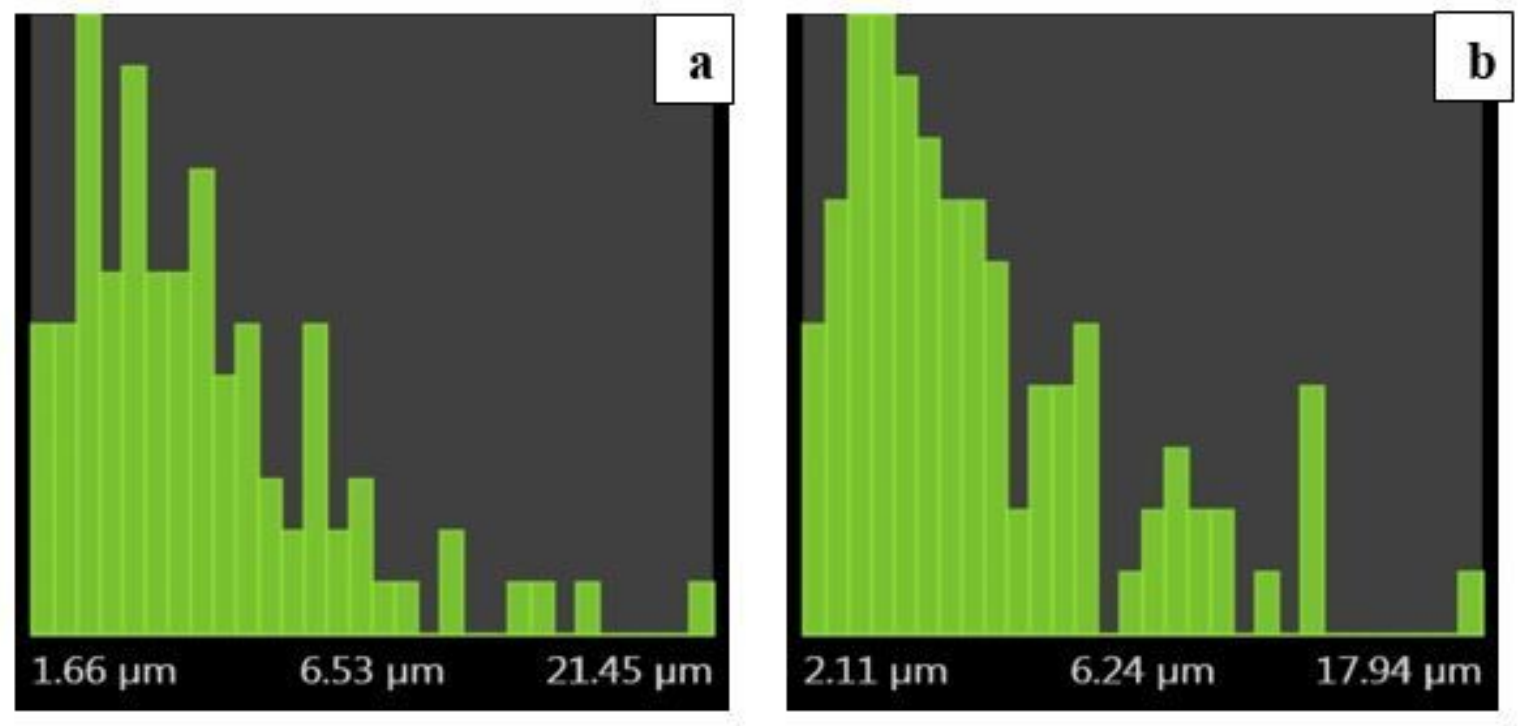

Figure 5

Fibre lengths from SEM micrographs for (a) BEC and (b) VSC (600× magnifications)

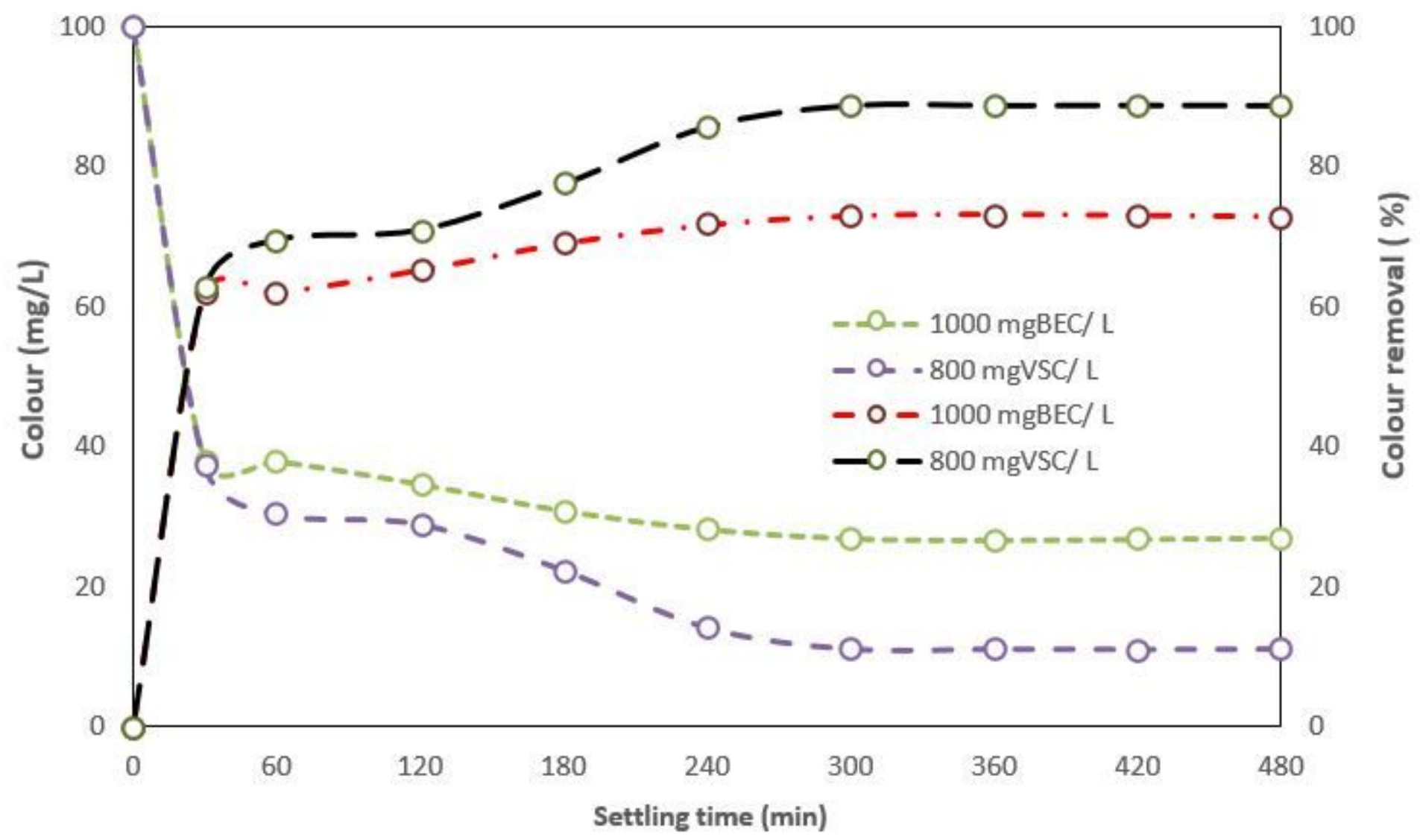

Figure 6

Colour removal and removal percentage utilising polymer coagulants as a function of settling time. 


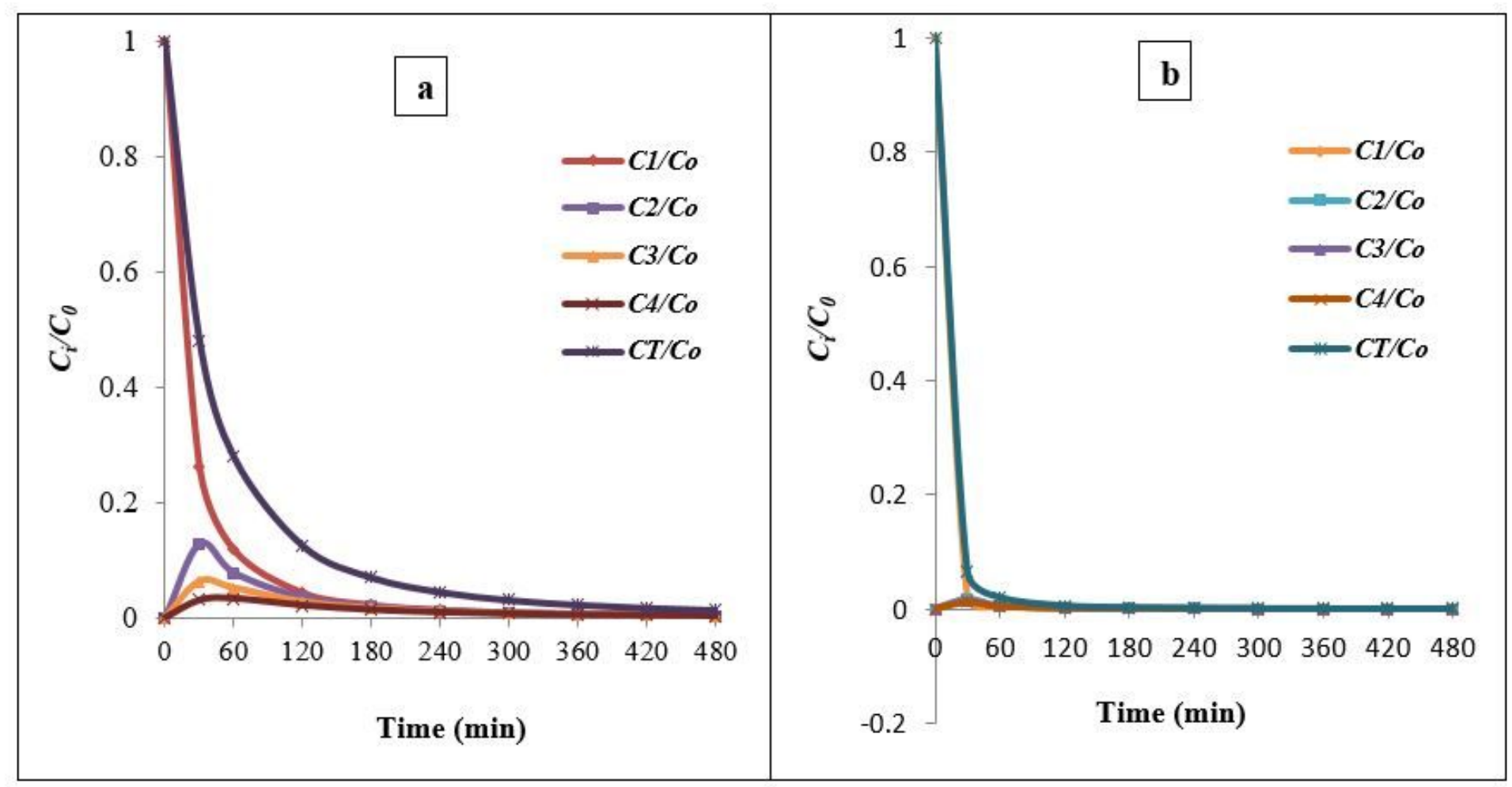

Figure 7

The decrease in the normalised number of overall particles with time for colour removal using (a) BEC@ 480 min, and 6.38 x 10-4 mg/Lmin, (b) VSC @ 480 min and K= 4.03 x 10-3 mg/Lmin. 

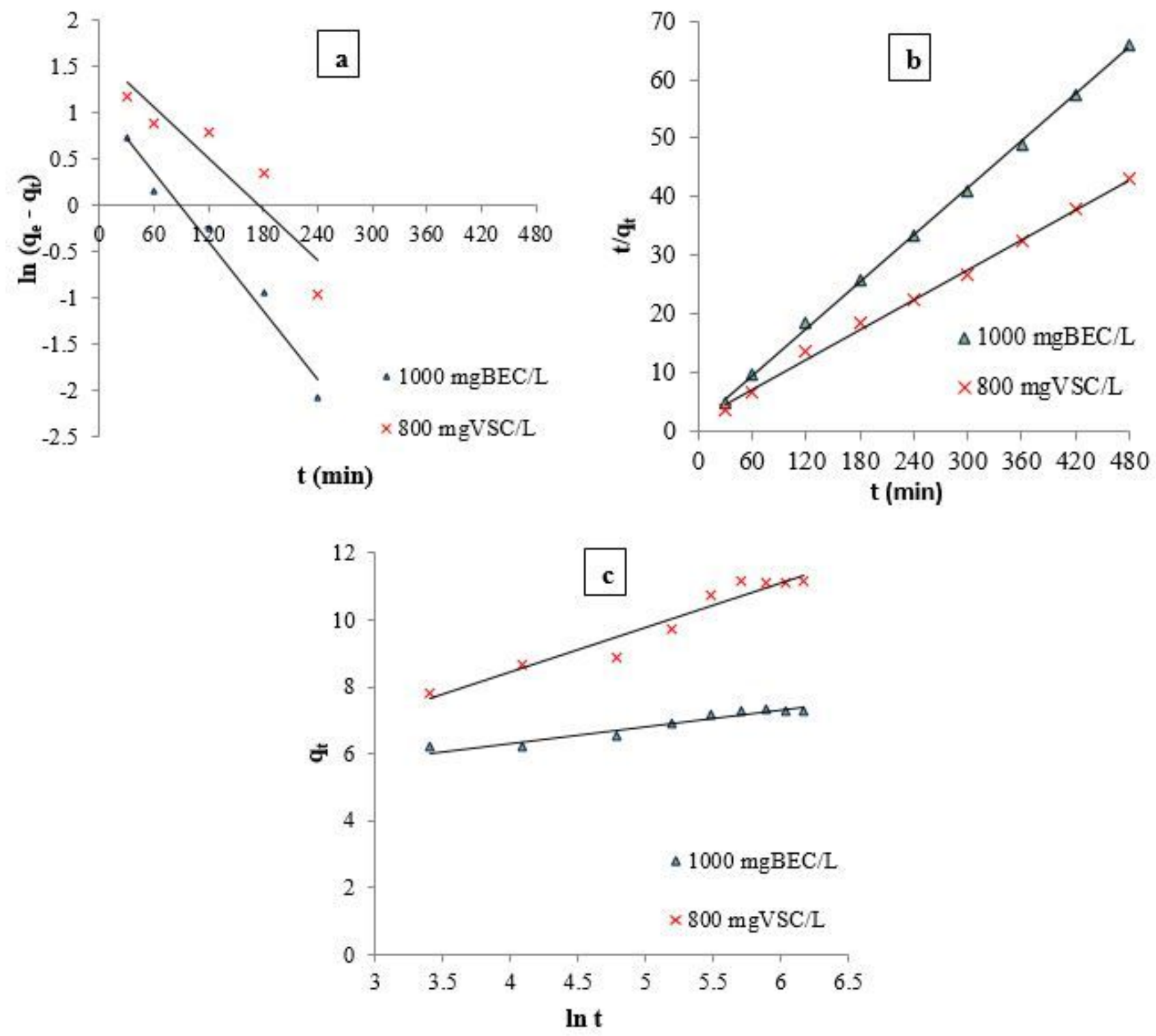

Figure 8

The plot of adsorption kinetics showing (a) pseudo-first-order, (b) pseudo-second-order and (c) Elovich kinetic plots. 


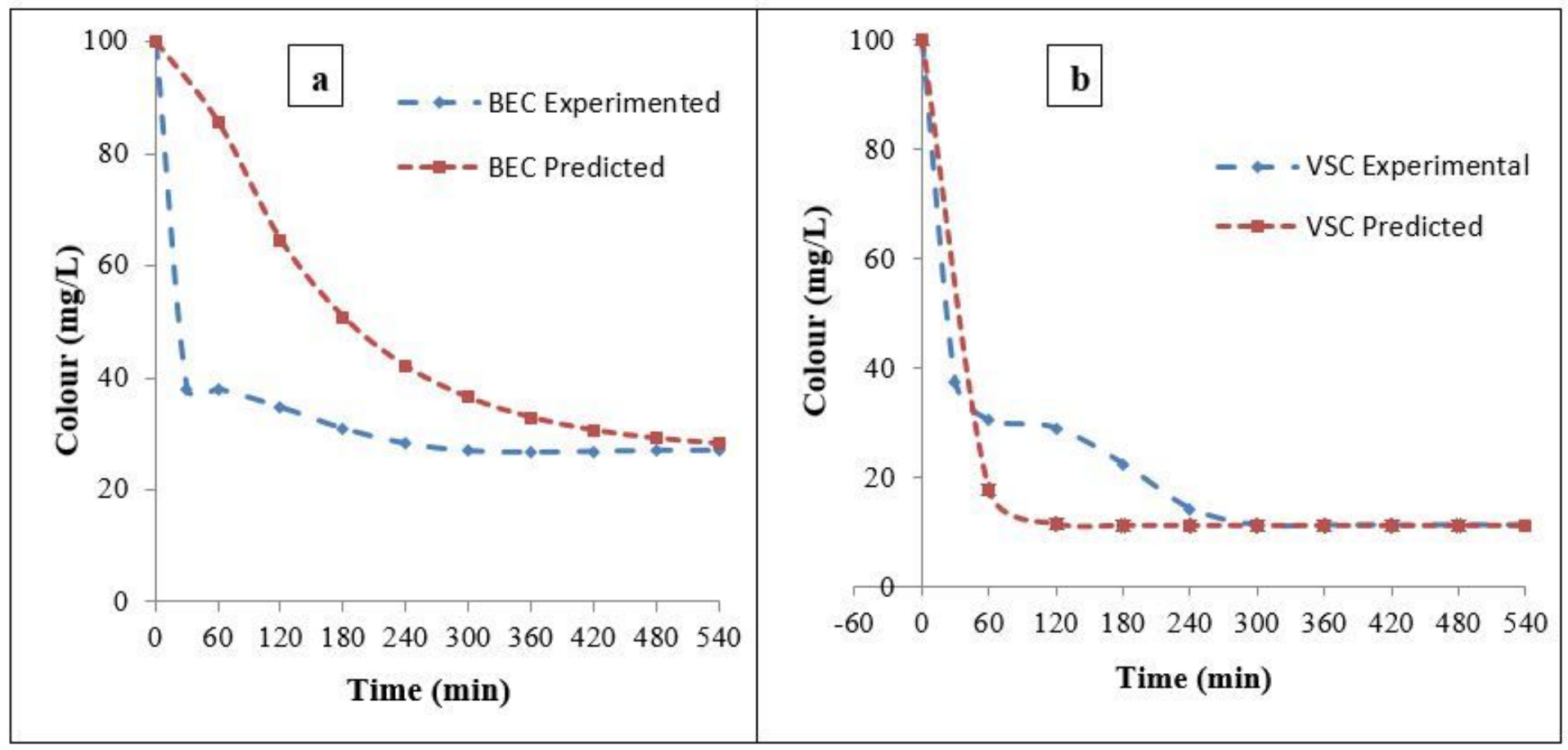

Figure 9

Particle rate transfer through coagulation-flocculation for; a. BEC and b. VSC.

\section{Supplementary Files}

This is a list of supplementary files associated with this preprint. Click to download.

- SUPPLEMENTARYFILECoagulationwithnaturalpolymers.docx 